\title{
Curvas de crescimento e de deposição dos componentes corporais em aves de postura de diferentes linhagens ${ }^{1}$
}

\section{Rafael Neme ${ }^{2}$, Nilva Kazue Sakomura ${ }^{2}$, Ellen Hatsumi Fukayama ${ }^{2}$, Ednardo Rodrigues Freitas ${ }^{2}$, Flávio Bello Fialho ${ }^{3}$, Kleber Tomás de Resende ${ }^{2}$, João Batista Kochenborger Fernandes ${ }^{4}$}

${ }^{1}$ Parte da tese de Doutorado do primeiro autor.

2 Departamento de Zootecnia - FCAVIUNESP, Jaboticabal, SP.

${ }^{3}$ Centro Nacional de Pesquisa de Uva e Vinho - Embrapa.

${ }^{4}$ Centro de Aqüicultura - UNESP Campus de Jaboticabal.

RESUMO - Objetivou-se com este trabalho determinar as curvas de crescimento de aves de postura das linhagens semipesadas Hy Line Marrom (HLM) e Hisex Marrom (HSM) e leves Hy Line W36 (HLW36) e Hisex Branca (HSB). Foram utilizadas 300 aves de cada linhagem, distribuídas em um delineamento experimental inteiramente casualizado, com quatro repetições de 75 aves por tratamento. Semanalmente, foram avaliados o peso vivo (PV), o peso de pena (PP) e a composição corporal de proteína, gordura, cinzas e água. As curvas de crescimento foram determinadas aplicando-se os dados na função de Gompertz. As aves semipesadas foram mais tardias para PV que as leves, com taxas de crescimento corporal e pesos à maturidade (PM) maiores. Aves da linhagem HLW36 foram 64,23 g mais leves à maturidade que as HSB. As respostas obtidas para o crescimento das penas e deposição protéica foram semelhantes, todavia, os PM foram maiores para as aves marrons que para as brancas. No entanto, para estes componentes, as Hy Line tiveram maiores deposições que as Hisex. A taxa de peso de pena à maturidade foi menor na linhagem HLW36, tornando-a três dias mais tardia em comparação à HSB. A menor deposição protéica no final do período de crescimento da HSM possibilitou o desvio da energia ingerida para deposição de gordura, resultando em PM superestimado em relação às aves HLM. As aves da linhagem Hy Line foram mais tardias na composição de cinzas, apresentando PM superiores ao das aves Hisex. Entre as variáveis estudadas, os PM foram sempre maiores nas aves Hy Line, no entanto, a deposição de água corporal nas aves Hisex foi maior, assim como as taxas máximas à maturidade foram mais tardias, o que justifica a semelhança no ganho de peso entre as diferentes linhagens, visto que os demais componentes estudados foram maiores para as Hy Line.

Palavras-chave: aves de postura, composição corporal, frangas, função de Gompertz

\section{Growth curves and deposition of body components in pullets of different strains}

\begin{abstract}
The growth curves of egg pullets of semi heavy: Hy Line Brown (HLB) and Hisex Brown (HSB) and light strains: Hy Line W36 (HLW36) and Hisex White (HSW) were evaluated. Three hundred birds of each strain were assigned to a completely randomized design with four replicates of 75 birds. Body weight (BW), feather weight (FW) and body depositions of protein, fat, ash and water were weekly measured. The growth curves were determined by Gompertz function with data collections. The semi heavy birds were later than the light ones for BW, with greater body growth rates and weights at maturity. The HLW36 were $64.23 \mathrm{~g}$ lighter at maturity than the HSW. Data obtained for feather growth and protein deposition were similar, but the semi heavy birds showed greater weight at maturity (WM) than the light ones. However, for these components, the birds Hy Line had larger depositions than Hisex. HLW36 strain had smaller feather rate at maturity, making it three days later than HSW. The lowest protein deposition in the end of growth period caused the deviation of energy ingested for fat deposition in HSB birds and overestimated the WM in relation to HLB birds. Hy Line birds had later body ash composition and showed greater WM than Hisex. Among the studied variables, Hy Line birds had always heavier WM, however, the body water content of Hisex birds was greater and the maximum rates at maturity were later. This fact explains the similarity in the weight gain among the studied strains, once other body components were greater for Hy Line birds.
\end{abstract}

Key Words: body composition, Gompertz function, laying birds, pullets

\section{Introdução}

As linhagens de postura utilizadas atualmente, em virtude do constante melhoramento genético, estão aumen- tando continuamente a produção de ovos, diminuindo o peso à maturidade fisiológica, a idade de pico de produção, o consumo de alimento e o ganho de peso. Desta forma, os programas nutricionais destas aves devem ser reavaliados 
periodicamente, de modo a determinar estratégias de alimentação próprias para os novos requerimentos fisiológicos das aves em crescimento (Summers, 1983; Leeson 1986).

Em uma revisão sobre as estratégias de alimentação para frangas no período de 1970 a 1992, Kwakkel (1999) constatou que as empresas fornecedoras de material genético enfatizavam a importância de as aves atingirem o chamado "peso alvo", tornando-se aptas à produção. As relações fisiológicas entre o peso alvo e a produção não eram tão claras e o peso corporal servia apenas como ferramenta para avaliar a fase de crescimento sob condições práticas. O período de crescimento era considerado não lucrativo e os requerimentos nutricionais não eram adequadamente definidos. Em uma etapa seguinte, os modelos de crescimento começaram a ser estudados e a configuração da curva de crescimento corporal passou a fornecer informações adicionais sobre o subseqüente desempenho das aves. Constatou-se então que diferentes curvas de crescimento podem afetar a composição corporal durante e ao final da fase de criação, tendo importante papel na maturidade fisiológica e sexual das aves de postura.

O início da postura pode ser determinado por inúmeros fatores inter-relacionados, como idade, peso corporal, gordura corporal, tecido magro e genética. Por isso, o estudo das curvas de crescimento, da composição corporal e das taxas de deposição dos tecidos corporais das diferentes linhagens torna-se importante para o entendimento de como as aves crescem e depositam seus tecidos, possibilitando a elaboração de programas nutricionais mais adequados.

Este estudo foi realizado com o objetivo de avaliar as curvas de crescimento, a composição corporal e as taxas de deposições de proteína, gordura, cinzas e água de quatro linhagens comerciais de aves de postura no período de 1 a 18 semanas de idade.

\section{Material e Métodos}

O experimento foi conduzido no Aviário Experimental do Departamento de Zootecnia da Faculdade de Ciências Agrárias e Veterinárias, FCAV-UNESP, em Jaboticabal - SP.

Foram utilizadas 1.200 pintainhas Hy Line Marrom (HLM) e Hisex Marrom (HSM) e Hy Line W-36 (HLW36) e Hisex Branca (HSB) de um dia de idade (300 de cada linhagem), alojadas em gaiolas de cria ( $11^{\mathrm{a}}$ a $6^{\underline{a}}$ semana) e recria (7a a $18^{\mathrm{a}}$ semana). As aves foram distribuídas em um delineamento experimental inteiramente casualizado, com quatro tratamentos e quatro repetições de 75 aves por tratamento para avaliação das linhagens leves (brancas) e semipesadas (marrons) nas primeiras 18 semanas de vida.
A temperatura (T) e a umidade relativa (UR) do ar dentro do galpão foram medidas diariamente durante todo o período experimental e apresentaram médias de $25,96^{\circ} \mathrm{C}$ e $58,73 \%$.

As aves foram alimentadas diariamente com rações formuladas para as linhagens leves (brancas) e semipesadas (marrons), de acordo com as exigências para cada fase de criação. As rações, à base de milho, farelo de soja e farelo de trigo, foram fornecidas à vontade e suas composições química e percentual são descritas na Tabela 1 .

Semanalmente, as aves e as rações foram pesadas para determinação do peso corporal médio, do ganho de peso e do consumo médio por ave de cada parcela. Em seguida, foram coletadas duas aves com o peso médio de cada parcela (oito aves por linhagem), separadas em gaiolas e submetidas a jejum de 24 horas para completo esvaziamento do trato gastrintestinal. As aves receberam apenas água (à vontade) e, após o jejum, foram pesadas, abatidas por deslocamento cervical, depenadas e pesadas novamente para determinação do peso em jejum (sem penas). As penas destinadas às análises laboratoriais foram coletadas anteriormente à depena, por meio de uma coleta padronizada, para evitar contaminação das amostras. As carcaças (ave inteira sem penas) foram congeladas, serradas em serra de fita e trituradas em moinho de carne industrial de $15 \mathrm{cv}$ por três vezes para melhor homogeneização da amostra. Da amostra total foram retiradas subamostras de $\pm 250 \mathrm{~g}$, que foram acondicionadas em bandejas plásticas e posteriormente secas em estufa de ventilação forçada por 72 horas, sendo processadas em moinho de bola para as análises laboratoriais.

Em todas as análises bromatológicas realizadas neste estudo, foram adotadas as metodologias descritas por Silva \& Queiroz (2002). Para determinação da MS, foram utilizadas estufas de ventilação forçada a $55^{\circ} \mathrm{C}$ e a $105^{\circ} \mathrm{C}$. Os valores de $\mathrm{PB}$ das amostras foram obtidos pelo método KJELDAHL e os de EE foram determinados via extração da gordura com éter de petróleo em sistema Soxhlet. As cinzas foram determinadas após a queima em mufla a $600^{\circ} \mathrm{C}$ durante 4 horas.

Os valores nutricionais dos alimentos foram obtidos de Rostagno et al. (2000). Para determinação das curvas de crescimento do peso vivo, do peso em jejum, do peso das penas e da composição química corporal das aves, obtidos semanalmente, os dados coletados foram aplicados na equação de crescimento descrita por Gompertz:

$$
\mathrm{Pt}=\mathrm{Pm} \cdot \exp \cdot\left\{-\exp \cdot\left[-\mathrm{b} \cdot\left(\mathrm{t}-\mathrm{t}^{*}\right)\right]\right\}
$$

em que: $\mathrm{Pt}=$ peso estimado $(\mathrm{g})$ do animal ao tempo $\mathrm{t}($ dias $)$; $\mathrm{Pm}=$ peso $(\mathrm{g})$ à maturidade do animal; $\mathrm{b}=$ constante de maturidade; $t^{*}=$ idade (dias) no ponto de inflexão. 
Tabela 1 - Composição das dietas experimentais

Table 1 - Ingredient composition of the experimental diets

\begin{tabular}{|c|c|c|c|c|c|c|}
\hline \multirow[t]{2}{*}{$\begin{array}{l}\text { Ingrediente } \\
\text { Ingredient (\%) }\end{array}$} & \multicolumn{2}{|c|}{$\begin{array}{l}1 \text { a } 6 \text { semanas } \\
1 \text { to } 6 \text { weeks }\end{array}$} & \multicolumn{2}{|c|}{$\begin{array}{l}7 \text { a } 12 \text { semanas } \\
7 \text { to } 12 \text { weeks }\end{array}$} & \multicolumn{2}{|c|}{$\begin{array}{c}13 \text { a } 18 \text { semanas } \\
13 \text { to } 18 \text { weeks }\end{array}$} \\
\hline & $\begin{array}{l}\text { Leve } \\
\text { Light }\end{array}$ & $\begin{array}{l}\text { Semipesada } \\
\text { Semi heavy }\end{array}$ & $\begin{array}{l}\text { Leve } \\
\text { Light }\end{array}$ & $\begin{array}{l}\text { Semipesada } \\
\text { Semi heavy }\end{array}$ & $\begin{array}{l}\text { Leve } \\
\text { Light }\end{array}$ & $\begin{array}{c}\text { Semipesada } \\
\text { Semi heavy }\end{array}$ \\
\hline Milho (Corn) & 59,342 & 59,289 & 61,663 & 63,232 & 61,786 & 58,703 \\
\hline Farelo de soja (Soybean meal) & 34,855 & 34,865 & 24,505 & 21,053 & 17,184 & 16,549 \\
\hline Farelo de trigo (Wheat meal) & - & - & 9,441 & 11,379 & 17,119 & 20,915 \\
\hline Calcário (Limestone) & 1,077 & 1,077 & 1,261 & 1,317 & 1,490 & 1,509 \\
\hline Supl. mineral ${ }^{1}$ (Premix mineral) & 0,250 & 0,250 & 0,250 & 0,250 & 0,250 & 0,250 \\
\hline Supl. vitamínico ${ }^{2}$ (Vvitamin premix) & 0,300 & 0,300 & 0,300 & 0,300 & 0,300 & 0,300 \\
\hline Cloreto de sódio (Sodium chloride) & 0,348 & 0,373 & 0,357 & 0,360 & 0,313 & 0,338 \\
\hline DL-metionina 99\% (DL-methionine 99\%) & 0,071 & 0,071 & 0,053 & 0,089 & 0,030 & 0,025 \\
\hline L-lisina $\mathrm{HCl}$ (L-lysine $\mathrm{HCl}$ 99\%) & - & - & 0,007 & 0,108 & 0,076 & - \\
\hline $\mathrm{EM}(\mathrm{kcal} / \mathrm{kg})(M E, \mathrm{kcal} / \mathrm{kg})$ & 2950 & 2950 & 2850 & 2850 & 2800 & 2750 \\
\hline Proteína bruta (\%) (Crude protein, \%) & 21,00 & 21,00 & 18,00 & 17,00 & 16,00 & 16,00 \\
\hline Cálcio (\%) (Calcium, \%) & 1,000 & 1,000 & 1,000 & 1,000 & 1,000 & 1,000 \\
\hline Fósforo disponível (\%) (Available phosphorus, \%) & 0,480 & 0,480 & 0,450 & 0,440 & 0,400 & 0,400 \\
\hline Fibra bruta (\%) (Crude fiber, \%) & 3,221 & 3,220 & 3,500 & 3,500 & 3,758 & 4,001 \\
\hline Metionina (\%) (Methionine, \%) & 0,480 & 0,480 & 0,420 & 0,440 & 0,367 & 0,360 \\
\hline Met. + Cistina (\%) (Methionine + Cystine, \%) & 0,815 & 0,815 & 0,725 & 0,732 & 0,650 & 0,645 \\
\hline Lisina (\%) (Lysine, \%) & 1,117 & 1,117 & 0,900 & 0,900 & 0,800 & 0,739 \\
\hline Treonina (\%) (Threonine, \%) & 0,816 & 0,816 & 0,686 & 0,639 & 0,594 & 0,591 \\
\hline Triptofano (\%) (Thryptophan, \%) & 0,262 & 0,262 & 0,215 & 0,198 & 0,183 & 0,185 \\
\hline Sódio $(\%)$ (Sodium, \%) & 0,180 & 0,190 & 0,180 & 0,180 & 0,160 & 0,170 \\
\hline Potássio (\%) (Potassium, \%) & 0,819 & 0,819 & 0,716 & 0,674 & 0,647 & 0,658 \\
\hline
\end{tabular}

${ }_{1}^{1}$ Níveis de garantia por quilo de produto (Guarantee levels per $\mathrm{kg}$ of product): $\mathrm{Fe}-35 \mathrm{~g}$, Cu-12 g, Co-2 g, Mn - $35 \mathrm{~g}, \mathrm{Zi}-30 \mathrm{~g}, \mathrm{I}-600 \mathrm{mg}$, Se - $70 \mathrm{mg}$; q.s.p. - $1.000 \mathrm{~g}$. 2 Níveis de garantia por quilo de produto (Guarantee levels per $\mathrm{kg}$ of product): vit. A $-4.500 .000 \mathrm{UI}$, vit. $\mathrm{D}_{3}-1.100 .000$, UI, vit. E - $4.400 \mathrm{mg}$; vit. $\mathrm{K}_{3}-860 \mathrm{mg}$, vit. $B_{1}-44 \mathrm{mg}$, vit. $B_{2}-2.200 \mathrm{mg}$, vit. $B_{12}-5.000 \mathrm{mcg}$, pantotenato de cálcio (calcium pantothenic) - $5.000 \mathrm{mg}$; niacina (niacin) - $10.600 \mathrm{mg}$, piridoxina (piridoxin) $45 \mathrm{mg}$; biotina (biotin) - $10 \mathrm{mg}$; colina (coline) - $100 \mathrm{~g}$; ácido fólico (folic acid) - $180 \mathrm{mg}$; antibiótico (antibiotic) - $40 \mathrm{~g}$; antioxidante (antioxidant) - $50 \mathrm{~g}$; q.s.p. - $1.000 \mathrm{~g}$.

Os dados obtidos semanalmente para as diferentes variáveis estudadas foram submetidos ao modelo proposto por Gompertz, utilizando-se o programa estatístico Statistica (1996), gerando os parâmetros e os coeficientes de determinação das equações para cada linhagem, obtendo-se as taxas de crescimento semanal pela derivada da equação de Gompertz. Para comparação da composição corporal das aves, foram utilizadas equações alométricas relacionando a quantidade de cada componente corporal e o peso vivo em jejum das aves (PV) ao longo do período de crescimento. Para verificar se as equações obtidas para cada componente foram similares, as linhagens foram comparadas pelo programa estatístico Estat-Unesp, utilizando-se o teste de homogeneidade de coeficientes de regressão (Steel \& Torrie, 1980).

\section{Resultados e Discussão}

As curvas de crescimento para peso vivo diferiram significativamente $(\mathrm{P}<0,05)$ entre as linhagens marrons $\mathrm{e}$ brancas, apresentando um padrão de crescimento para as aves leves e outro para as aves semipesadas. Assim, foi elaborada uma única equação alométrica para as linhagens marrons e outra para as linhagens brancas, descrevendo o PV em função da idade (Tabela 2). Fukayama (2002) encontrou resultados semelhantes para ganho de peso dessas linhagens e relataram que as aves semipesadas apresentaram maiores pesos, independentemente da temperatura ambiente $\left(12,18,24,30\right.$ e $\left.36^{\circ} \mathrm{C}\right)$.

Com base nos parâmetros estimados pela função de Gompertz (Tabela 3), observou-se, pelo peso vivo, que as taxas de maturidade (b) das aves Hy Line W36 (HLW36) foram superiores às das Hy Line Marrom (HLM), Hisex Marrom (HSM) e Hisex Branca (HSB), de modo que as Hy Line W36 alcançaram o peso corporal adulto mais rapidamente que as demais linhagens estudadas.

Os resultados indicam que as menores taxas de maturidade das linhagens HLM e HSM resultaram em tempo maior para que essas aves atingissem suas taxas máximas de crescimento corporal (59 dias) em relação às HLW36 
Tabela 2 - Equações de regressão do peso vivo, em função da idade das aves

Table 2 - $\quad$ Regression equations of body weight on bird age

\begin{tabular}{llll}
\hline $\begin{array}{l}\text { Linhagem } \\
\text { Strain }\end{array}$ & $\begin{array}{c}\text { Equação } \\
\text { Equation }\end{array}$ & $\mathrm{R}^{2}$ & $\mathrm{P}$ \\
\hline \multicolumn{3}{c}{$\begin{array}{l}\text { Peso vivo } \\
\text { Body weight }\end{array}$} \\
& & \\
& &
\end{tabular}

Semipesadas $^{1} \log \mathrm{PV}=0,831+1,106 . \log$ Idade $0,98 \quad 0,001$ Semi heavy

Leves $^{2} \quad \log \mathrm{PV}=0,685+1,228 . \log$ Idade $0,98 \quad 0,001$

Light

${ }^{1}$ HLM e HSM, ${ }^{2}$ HLW36 e HSB, PV = Peso vivo (Live weight).

(52 dias) e, conseqüentemente, atingissem maiores pesos corporais à maturidade (HLM, 2060; HSM, 2064 e HLW36, $1.533 \mathrm{~g}$ ). Verificou-se também, pelo peso vivo, que a linhagem leve HSB foi intermediária às demais linhagens estudadas, sendo quatro dias mais precoce que as semipesadas e três dias mais tardia que a linhagem HLW36, apesar do semelhante peso à maturidade.

O período em que a taxa de crescimento é máxima ( $t *$ é denominado ponto de inflexão da curva de crescimento e representa o exato momento em que a taxa de crescimento passa de crescente para decrescente (Figura 1). O padrão da curva de crescimento é então alterado de côncavo para convexo, como reportado por Longo (2000) e Kessler et al. (2000). Os resultados obtidos para a variável peso das aves depenadas foram semelhantes aos descritos para peso vivo.

Segundo os manuais das linhagens comerciais leves presentes no mercado brasileiro, a linhagem HLW36 é a de menor peso corporal. Portanto, esperava-se que atingisse o ponto de inflexão da curva de crescimento mais precocemente que as demais aves de sua categoria, assim como observado neste ensaio. Nota-se também que o peso à maturidade das aves HLW36 foi $65 \mathrm{~g}$ menor que o das HSB, muito próximo da diferença de peso encontrada entre os manuais das linhagens, de $80 \mathrm{~g}$ (Tabela 3 - rodapé).

É interessante salientar que o PM, determinado pela função de Gompertz para cada linhagem, muitas vezes chamado peso adulto, aproxima-se do peso preconizado pelos manuais para o início do pico de postura (Tabela 3 rodapé), indicando boa assertividade das equações. Essa relação reforça o argumento de que o pleno desenvolvimento do sistema reprodutivo das aves não é atingido completamente no início da postura, mas sim no pico de postura (Kwakkel, 1999).

Para todas as linhagens estudadas, o ponto de inflexão de cada curva apresentou-se anteriormente ao centro da curva de crescimento, ou seja, antes da metade do período avaliado (126 dias ou 18 semanas). Ocorreu aos 46,83\% (59 dias) para as aves semipesadas, aos 41,27\% (52 dias) para as HLW36 e aos 43,65\% (55 dias) para as HSB. Esses dados indicam mais uma vez que as aves brancas são mais precoces que as marrons, pois atingiram as maiores taxas de desenvolvimento corporal em menor tempo. Estes resultados estão próximos aos reportados por Braccini Neto et al. (1993), que relataram que o ponto de inflexão ocorreu na metade da curva de crescimento para aves de postura. No entanto, Lopes (1983) e Longo (2000) encontraram pontos de inflexão aos 30,0 e $30,8 \%$ do período estudado com frangos de corte, indicando maior

Tabela 3 - Estimativas dos parâmetros das equações de Gompertz e coeficientes de determinação $\left(R^{2}\right)$ para peso vivo e peso em jejum (sem penas) de diferentes linhagens de aves

Table 3 - Parameter estimates of Gompertz equations and coefficients of determination $\left(R^{2}\right)$ for body and fasting (defeathered) weights of different pullets strains

\begin{tabular}{|c|c|c|c|c|}
\hline $\begin{array}{l}\text { Parâmetro } \\
\text { Parameter }\end{array}$ & $\begin{array}{c}\text { Hy Line Marrom } \\
\text { Hy Line Brown }\end{array}$ & $\begin{array}{c}\text { Hy Line W36 } \\
\text { Hy Line W36 }\end{array}$ & $\begin{array}{l}\text { Hisex Marrom } \\
\text { Hisex Brown }\end{array}$ & $\begin{array}{l}\text { Hisex Branca } \\
\text { Hisex White }\end{array}$ \\
\hline \multicolumn{5}{|l|}{$\begin{array}{l}\text { Peso vivo } \\
\text { Body weight }\end{array}$} \\
\hline $\begin{array}{l}\operatorname{Pm}(\mathrm{g}) \\
\mathrm{b}-\text { por dia (per day) } \\
\mathrm{t}^{*}-\operatorname{dias} \text { (days) } \\
\mathrm{R}^{2}\end{array}$ & $\begin{array}{c}2060 \\
0,023 \\
59 \\
0,99\end{array}$ & $\begin{array}{c}1533 \\
0,026 \\
52 \\
0,99\end{array}$ & $\begin{array}{c}2064 \\
0,023 \\
59 \\
0,99\end{array}$ & $\begin{array}{c}1598 \\
0,023 \\
55 \\
0,99\end{array}$ \\
\hline \multicolumn{5}{|c|}{$\begin{array}{l}\text { Peso em jejum, sem penas } \\
\text { Fasting weight (defeathered) }\end{array}$} \\
\hline $\begin{array}{l}\operatorname{Pm}(\mathrm{g}) \\
\mathrm{b}-\text { por dia (per day) } \\
\mathrm{t}^{*}-\text { dias (day) } \\
\mathrm{R}^{2}\end{array}$ & $\begin{array}{c}1769 \\
0,024 \\
60 \\
0,99\end{array}$ & $\begin{array}{c}1261 \\
0,026 \\
51 \\
0,99\end{array}$ & $\begin{array}{c}1764 \\
0,024 \\
60 \\
0,99\end{array}$ & $\begin{array}{c}1345 \\
0,024 \\
55 \\
0,99\end{array}$ \\
\hline
\end{tabular}

$\mathrm{PM}=$ peso à maturidade (maturity weight); $\mathrm{b}=$ constante de maturidade/constant of maturity; $\mathrm{t}^{\star}=$ tempo em que a taxa de maturidade é máxima (time that the maturity rate is maximum).

Peso das aves recomendado pelos manuais no pico de postura (g) (Body weight recommended for strains at production peak). (1980-HLM) (1520-HLW36), (1960-HSM) e (1600-HSB). 

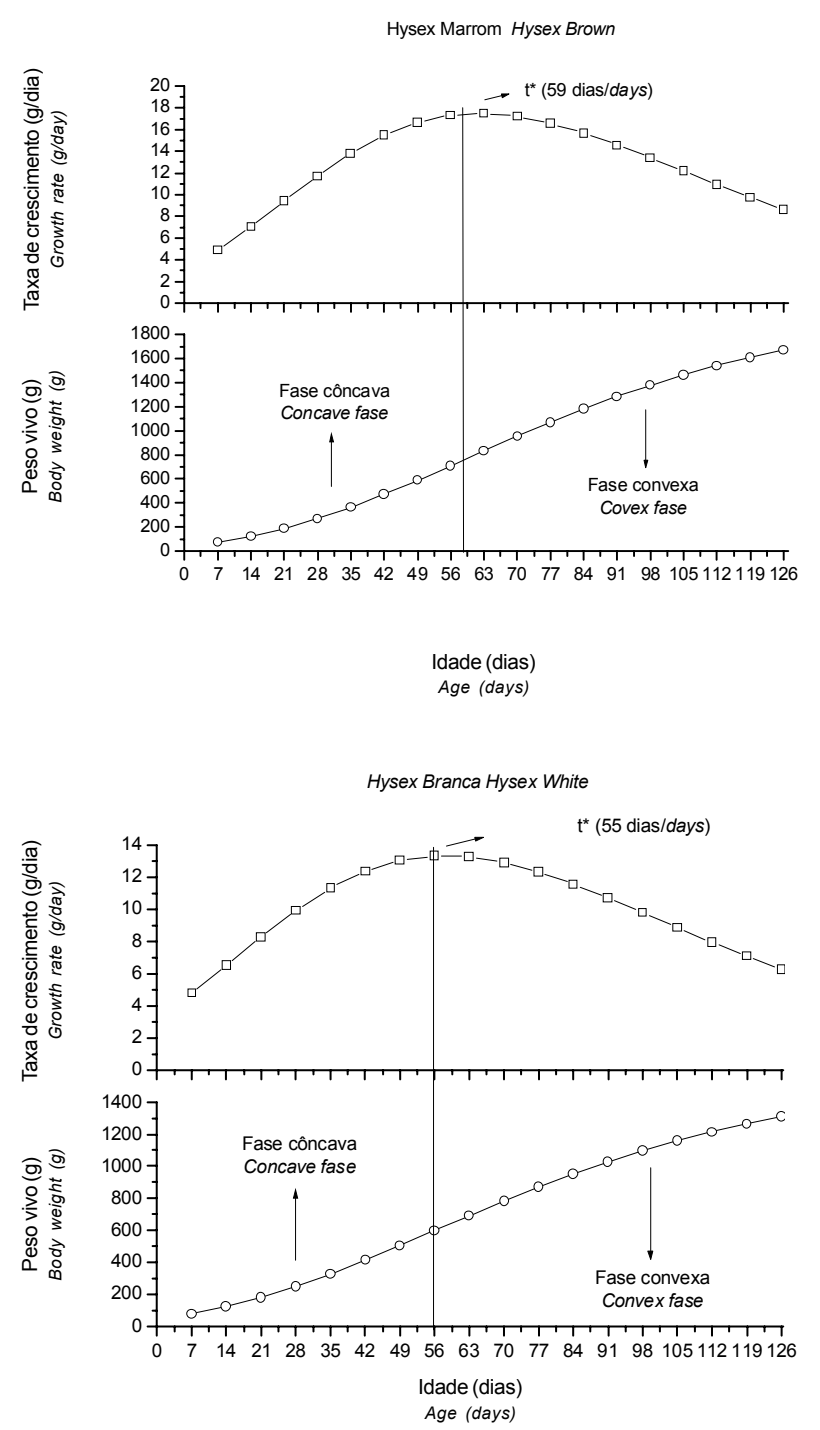
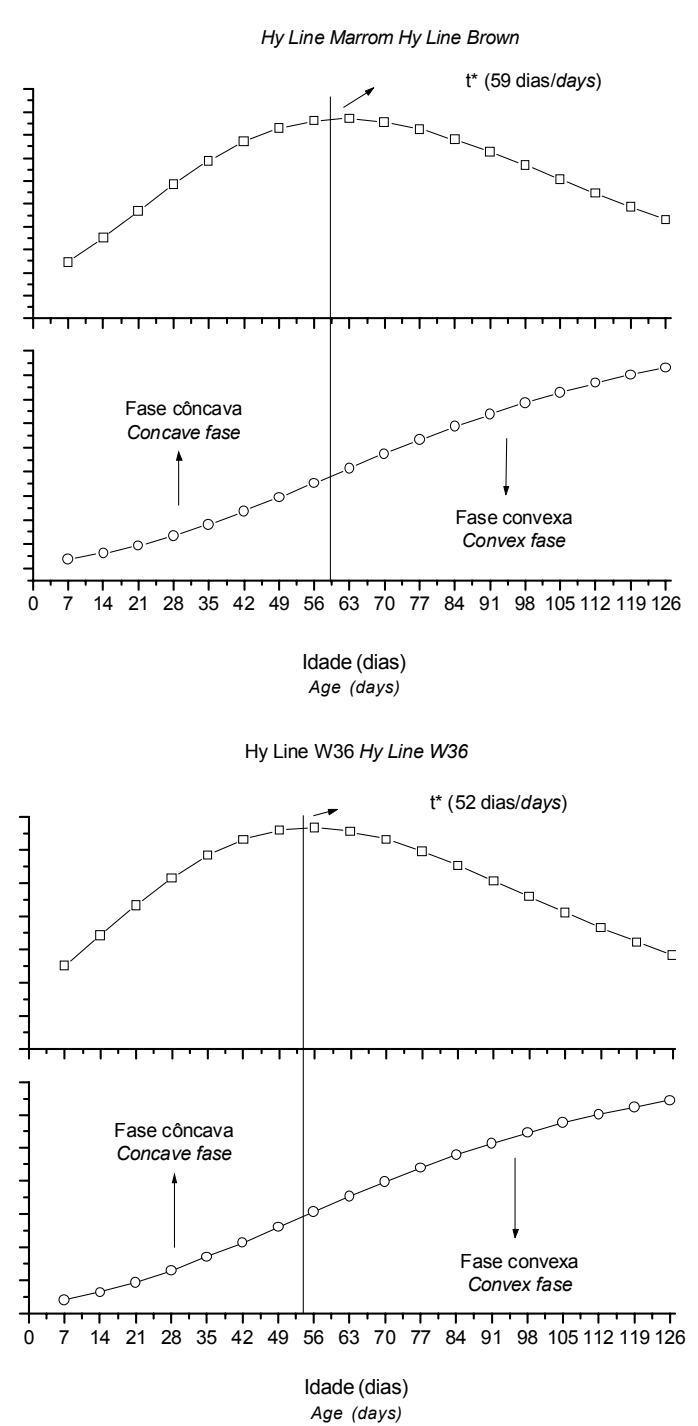

Figura 1 - Taxas e curvas de crescimento do PV em função da idade das aves, de acordo com a equação de Gompertz para cada linhagem. Figure 1 - Growth rates and curves for body weight according to the bird age, by Gompertz equation for each strain.

precocidade dos frangos de corte em comparação às aves de postura. Uma vez que as linhagens de postura modernas são produzidas visando principalmente à maior produção de ovos, a seleção de linhagens com menor peso à maturidade, menor consumo de alimento e capacidade para manter altos índices produtivos, resultam em redução dos custos de produção.

A comparação dos coeficientes das equações para peso de pena (Tabela 4) indicou diferença $(\mathrm{P}<0,05)$ entre as aves leves e semipesadas, de modo que as aves marrons apresentaram maiores quantidades de pena, como verificado para a variável peso vivo.

O peso de penas neste ensaio (Tabela 5 e Figura 2) apresentou o mesmo comportamento entre as aves das linhagens Hy Line e Hisex, tendo as aves marrons peso de pena à maturidade numericamente maior ( $165 \mathrm{~g}$ para HLM e $157 \mathrm{~g}$ para HSM) que o das aves brancas (158 g para HLW36 e $142 \mathrm{~g}$ para HSB). No entanto, observou-se o inverso para a quantidade relativa de penas: 8,$95 ; 8,44 ; 10,38$ e $9,45 \%$ para as aves HLM, HSM e HLW36, HSB, respectivamente.

Balnave (1974) e Hughes (1980) também constataram diferenças de densidade de penas entre diferentes linhagens e atribuíram-nas ao aumento na produção de calor pelas aves.

$\mathrm{O}$ peso de pena à maturidade das aves Hy Line foi maior que o das Hisex (Tabela 5 - funções de Gompertz), tanto para as aves brancas como para as marrons. As aves da linhagem HLW36 apresentaram menor taxa de maturidade $(0,026)$ e foram três dias mais tardias que as HSB. Esse comportamento diferiu do observado para $\mathrm{PV}$, em que as aves HLW36 foram três dias mais precoces.

Evidenciou-se neste estudo que a seleção de aves com menores pesos corporais não resulta em mesmo padrão de redução no peso corporal e das penas. Considerando as 
Tabela 4 - Equações de regressão do peso de pena $(\mathrm{kg})$ em função da idade (dias) das aves

Table 4 - Regression equations of feather weight $(\mathrm{kg})$ on bird age (days) growth

\begin{tabular}{|c|c|c|c|}
\hline Linhagem & Equação & $\mathrm{R}^{2}$ & $\mathrm{P}$ \\
\hline Strain & Equation & & \\
\hline
\end{tabular}

Semipesadas $^{1} \log \mathrm{PP}=-0,9504+1,5091 . \log$ idade $0,98 \quad 0,001$ Semi heavy

Leves $^{2} \quad \log \mathrm{PP}=-0,8706+1,4796 . \log$ idade $\quad 0,99 \quad 0,001$ Light

${ }^{1}$ HLM e HSM, ${ }^{2}$ HLW36 e HSB. PP = Peso de pena (feather weight).

altas temperaturas encontradas em algumas regiões do Brasil, torna-se importante avaliar a influência do empenamento sobre as exigências energéticas das aves.

O crescimento corporal é determinado pela deposição de proteína, gordura e cinzas. A deposição e as proporções destes componentes individualmente em cada órgão corporal determinam a idade fisiológica das aves e seu estágio de maturidade (Rickefs, 1985).

De modo semelhante ao observado para o peso das penas à maturidade, os pesos à maturidade para deposição de proteína nas linhagens HLM e HLW36 foram maiores que os das aves HSM e HSB, resultando em uma diferença de $19 \%$ entre as aves marrons e de $33 \%$ entre as brancas (Tabela 6).

O teor de PB das penas é muito alto e praticamente constante (Rabello, 2001), variando apenas quanto à quantidade depositada com o desenvolvimento da ave. As análises de $\mathrm{PB}$ realizadas neste estudo apresentaram pouca variação entre as diferentes linhagens estudadas, verificando-se média geral de $84,47 \% \pm 0,63$ de PB entre as linhagens. Assim, parte do maior peso de penas à maturidade pode ser atribuída à maior deposição de proteína nas aves, que foi 5,0\% maior para HLM em relação à HSM e 11,27\% maior para HLW36 em relação à HSB.

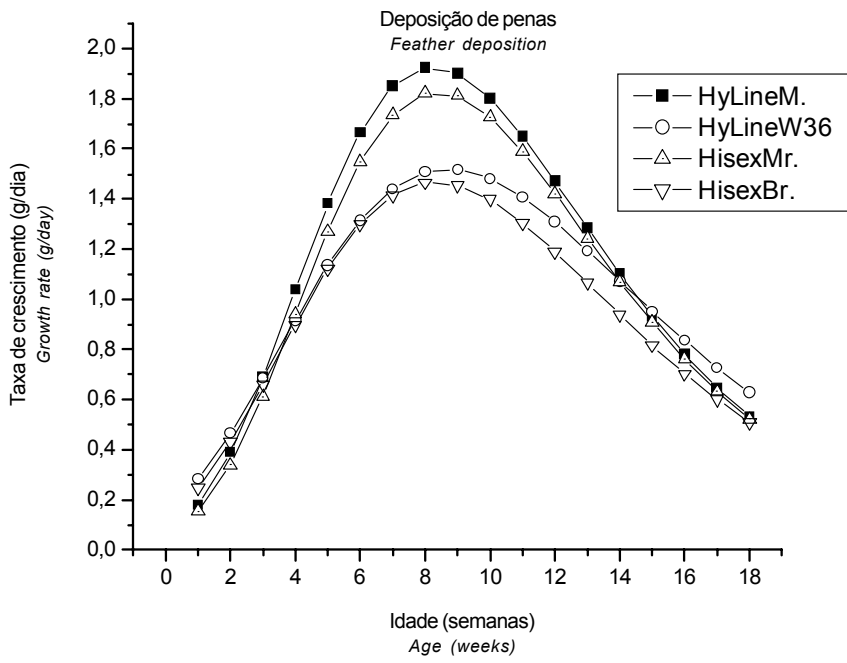

Figura 2 - Efeito da idade sobre a taxa de deposição de pena nas linhagens estudadas.

Figure 2 - Feather deposition rate according to the age and strain.

A maior deposição protéica nas aves da linhagem Hy Line em relação às Hisex resultou na necessidade de maior tempo para atingirem a maturidade. As aves marrons apresentaram maior peso à maturidade para deposição protéica em comparação às brancas (Tabela 6).

Após atingirem a taxa máxima de deposição protéica, as aves da linhagem Hisex apresentaram redução mais acentuada na taxa de deposição deste componente corporal, o que pôde ser constatado pelo cálculo das médias das taxas de deposição protéica antes e depois do ponto de inflexão de cada curva. Para as aves marrons, estas taxas foram de 3,97 e 3,84 g/dia antes e 5,32 e 4,63 g/dia depois do ponto de inflexão para HLM e HSM, respectivamente. Assim, a diferença na deposição de proteína variou de 3,39\% (antes) para $14,90 \%$ depois do ponto de inflexão da curva de crescimento. Entre as aves brancas, essas diferenças foram mais acentuadas, passando de 3,37 e 3,12 g/dia antes do ponto de inflexão (diferença de 8,0\%) para 4,32 e 3,38 g/dia depois do ponto de inflexão (diferença de 27,81\%) para HLW36 e HLB, respectivamente (Figura 3 ).

Tabela 5 - Estimativas dos parâmetros das equações de Gompertz e coeficientes de determinação $\left(R^{2}\right)$ para peso das penas de diferentes linhagens

Table 5 - Parameters estimates of Gompertz equations and coefficients of determination $\left(R^{2}\right)$ for feather weight of different strains

\begin{tabular}{|c|c|c|c|c|}
\hline $\begin{array}{l}\text { Peso das penas } \\
\text { Feather weight }\end{array}$ & $\begin{array}{c}\text { Hy Line Marrom } \\
\text { Hy Line Brown }\end{array}$ & $\begin{array}{l}\text { Hy Line W36 } \\
\text { Hy Line W36 }\end{array}$ & $\begin{array}{l}\text { Hisex Marrom } \\
\text { Hisex Brown }\end{array}$ & $\begin{array}{c}\text { Hisex Branca } \\
\text { Hisex White }\end{array}$ \\
\hline Pm（g) & 165 & 158 & 157 & 142 \\
\hline b - por dia (per day) & 0,032 & 0,026 & 0,032 & 0,028 \\
\hline $\mathrm{R}^{2}$ & 0,98 & 0,99 & 0,93 & 0,97 \\
\hline
\end{tabular}

$\mathrm{PM}=$ peso à maturidade (maturity weight) $\mathrm{b}=$ constante de maturidade (constant of maturity); $\mathrm{t}^{\star}=$ tempo em que a taxa de maturidade é máxima (time that the maturity rate is maximum). 
Tabela 6 - Estimativas dos parâmetros das equações de Gompertz e coeficientes de determinação $\left(R^{2}\right)$ para deposição de proteína, gordura, cinzas e água corporais das linhagens de reposição estudadas

Table 6 - Estimates of Gompertz equations and coefficients of determination $\left(R^{2}\right)$ for depositions of body protein, fat, ash and water of pullets

\begin{tabular}{|c|c|c|c|c|}
\hline $\begin{array}{l}\text { Variável } \\
\text { Variable }\end{array}$ & $\begin{array}{c}\text { Hy Line Marrom } \\
\text { Hy Line Brown }\end{array}$ & $\begin{array}{l}\text { Hy Line W36 } \\
\text { Hy Line W36 }\end{array}$ & $\begin{array}{l}\text { Hisex Marrom } \\
\text { Hisex Brown }\end{array}$ & $\begin{array}{c}\text { Hisex Branca } \\
\text { Hisex White }\end{array}$ \\
\hline \multicolumn{5}{|l|}{ Proteína (Protein) } \\
\hline $\begin{array}{l}\mathrm{PM}(\mathrm{g}) \\
\mathrm{b}(\text { por dia) (per day) } \\
\mathrm{t}^{*}(\text { dias }) \text { (days) } \\
\mathrm{R}^{2}\end{array}$ & $\begin{array}{c}782 \\
0,0220 \\
71 \\
0,99\end{array}$ & $\begin{array}{c}678 \\
0,0201 \\
71 \\
0,99\end{array}$ & $\begin{array}{c}657 \\
0,0257 \\
63 \\
0,99\end{array}$ & $\begin{array}{c}509 \\
0,0241 \\
60 \\
0,99\end{array}$ \\
\hline \multicolumn{5}{|l|}{ Gordura (Fat) } \\
\hline $\begin{array}{l}\mathrm{PM}(\mathrm{g}) \\
\mathrm{b}(\text { por dia) (per day) } \\
\mathrm{t}^{*} \text { (dias) (days) } \\
\mathrm{R}^{2}\end{array}$ & $\begin{array}{c}731 \\
0,0154 \\
116 \\
0,99\end{array}$ & $\begin{array}{c}811 \\
0,0122 \\
133 \\
0,97\end{array}$ & $\begin{array}{c}2264 \\
0,0091 \\
198 \\
0,98\end{array}$ & $\begin{array}{c}790 \\
0,1157 \\
148 \\
0,97\end{array}$ \\
\hline \multicolumn{5}{|l|}{ Cinzas (Ashes) } \\
\hline $\begin{array}{l}\mathrm{PM}(\mathrm{g}) \\
\mathrm{b}(\text { por dia) (per day) } \\
\mathrm{t}^{*} \text { (dias) (days) } \\
\mathrm{R}^{2}\end{array}$ & $\begin{array}{c}76 \\
0,0233 \\
65 \\
0,99 \\
\end{array}$ & $\begin{array}{c}55 \\
0,0235 \\
60 \\
0,99 \\
\end{array}$ & $\begin{array}{c}64 \\
0,0273 \\
55 \\
0,98 \\
\end{array}$ & $\begin{array}{c}50 \\
0,0264 \\
52 \\
0,98\end{array}$ \\
\hline \multicolumn{5}{|l|}{ Água (Water) } \\
\hline $\begin{array}{l}\mathrm{PM}(\mathrm{g}) \\
\mathrm{b} \text { (por dia) (per day) } \\
\mathrm{t}^{*}(\text { dias }) \text { (days) } \\
\mathrm{R}^{2}\end{array}$ & $\begin{array}{c}681 \\
0,0309 \\
45 \\
0,99\end{array}$ & $\begin{array}{c}457 \\
0,0393 \\
36 \\
0,98\end{array}$ & $\begin{array}{c}757 \\
0,0270 \\
50 \\
0,99\end{array}$ & $\begin{array}{c}589 \\
0,0288 \\
45 \\
0,99\end{array}$ \\
\hline
\end{tabular}

$\mathrm{PM}=$ peso à maturidade (maturity weight) $; \mathrm{b}=$ constante de maturidade (constant of maturity); $\mathrm{t}^{*}=$ tempo em que a taxa de maturidade é máxima (time that the maturity rate is maximum).

Como ocorre com a maioria dos animais, à medida que envelhecem, as aves depositam mais gordura corporal. A deposição de proteína (carne magra) é estreitamente controlada pela genética e, portanto, há um limite para sua deposição diária, independentemente de sua ingestão. Porém, a quantidade de gordura depositada em qualquer fase de desenvolvimento dos animais é diretamente relacionada à quantidade de nutrientes (proteínas, carboidratos $\mathrm{e}$ gorduras) disponíveis para síntese, independentemente da fonte (Kessler \& Snizek, 2001).

Observando-se os dados obtidos para deposição de gordura corporal (Tabela 6 e Figura 4), verifica-se que as aves da linhagem HSM apresentaram peso à maturidade superestimado se comparado ao peso à maturidade das aves HLM.

A partir do ponto de inflexão, onde a taxa de crescimento protéico foi máxima, ocorreu uma alteração no metabolismo das aves, que passaram a destinar gradualmente boa parte da energia ingerida para acúmulo de gordura corporal, compondo-se, assim, a reserva de energia necessária para o início da vida reprodutiva. Esse processo ocorreu primeiramente com as aves HSM, cujo acúmulo de gordura corporal foi maior nas últimas semanas da fase de crescimento, resultando na antecipação, por algumas aves, do início da postura e no aparecimento dos primeiros ovos ao final da $16^{\mathrm{a}}$ semana, o que está de acordo com os dados observados

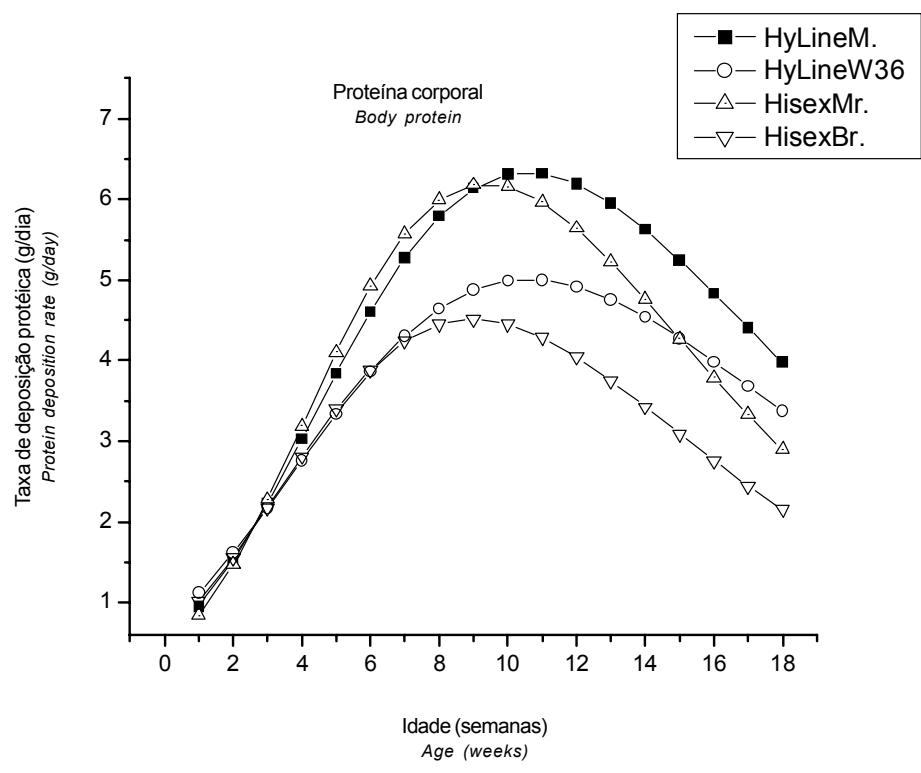

Figura 3 - Taxa de deposição protéica, em função da idade e linhagem.

Figure 3 - Protein deposition rate according to the age and strain.

por Brody et al. (1984) e Baker (1985), sugerindo que a gordura corporal é um fator crítico para o início da puberdade das galinhas. Ressalta-se que as aves HSM não apresentaram maiores quantidades de gordura na carcaça ao término do período de crescimento, mas sim uma diferença na 
taxa de deposição ao longo da idade quando comparadas às aves HLM.

Os dados da Tabela 7 auxiliam no entendimento das diferenças nas taxas de deposição de gordura entre as linhagens semipesadas. A aves HLM apresentaram maior deposição relativa de gordura até os 56 dias de idade; a partir deste ponto e até 126 dias de idade, a linhagem HSM teve taxa de deposição relativa de gordura maior que as HLM, recuperando as menores deposições de gordura da fase anterior.

O maior crescimento relativo das aves HSM e suas conseqüentes maiores taxas de deposição de gordura nas últimas cinco semanas do período experimental resultaram na descaracterização do modelo de crescimento sigmoidal obtido, diferenciando-as das demais linhagens, o que superestimou o peso de gordura corporal à maturidade (Figura 4).

De acordo com Kessler et al. (2000), à medida que o animal cresce, a participação da energia metabolizável de mantença aumenta, pois é positivamente correlacionada ao aumento do PV. Com a estabilização da deposição protéica e a posterior redução nas taxas de deposição, a energia líquida de produção passa a ser essencialmente direcionada para lipogênese.

Como as linhagens semipesadas receberam as mesmas rações durante todo o período experimental e apresentaram consumo de ração semelhante $(\mathrm{P}>0,05)$ e mesmo ganho de peso, verificou-se partição diferente da energia ingerida com a antecipação da maturidade sexual das aves HSM. Assim, o nível energético da ração recomendado nesta fase de crescimento parece não ser o mesmo para as aves HLM e HSM.

De acordo com os dados obtidos para as aves leves, as aves HLW36 alcançaram a taxa máxima de gordura à matu-

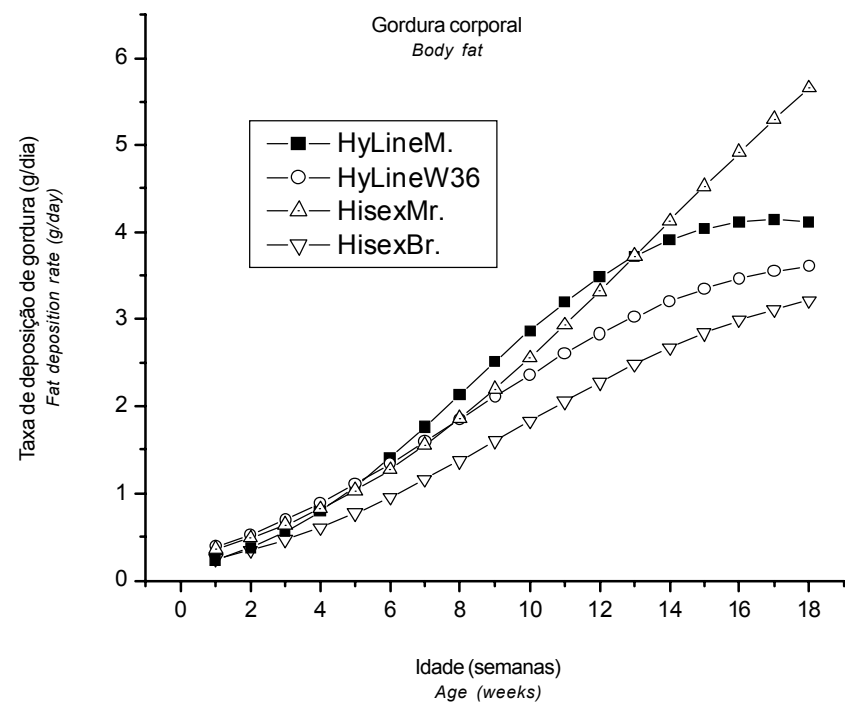

Figura 4 - Efeito da idade sobre a taxa de deposição de gordura. Figure 4 - Fat deposition rate according to the age and strain. ridade ( $\left.\mathrm{t}^{*}\right) 15$ dias mais cedo que as aves HSB (Tabela 6). Considerando ainda que estas aves apresentam peso de gordura à maturidade 2,66\% maior que o das aves HSB, a taxa de deposição deste componente deverá ser obrigatoriamente maior, como indicado na Figura 4. Assim, a média diária de deposição de gordura para todo o período de crescimento foi de $2,14 \mathrm{~g} /$ dia para HLW36 e de $1,72 \mathrm{~g} / \mathrm{dia}$ para as aves e HSB.

Boekholt et al.(1994) também verificaram, em frangos de corte de rápido crescimento e altas ingestões de energia, que, relativamente, a energia é retida mais como gordura que como proteína. Em animais com ganho de peso mais lento e mesmo peso final, a retenção de lipídeo foi menor e a de proteína, maior que em animais de rápido crescimento. Portanto, a seleção para favorecer o desenvolvimento protéico explica porque o crescimento rápido causou aumento na deposição de gordura em ratos (Thonney \& Ross, 1987).

Para o conteúdo de cinza corporal, a linhagem Hy Line também foi mais tardia, apresentando pesos à maturidade superiores aos das aves Hisex (Tabela 6). As aves marrons tiveram peso à maturidade superior ao das aves brancas. Entre as aves semipesadas, as HLM foram dez dias mais tardias e apresentaram peso à maturidade $18,75 \%$ maior que o das HSM. Entre as aves leves, as HLW36 foram oito dias mais tardias e apresentaram peso à maturidade $10 \%$ maior.

Quanto à composição química corporal à maturidade, à exceção da gordura corporal das aves HSM, os pesos de todos os componentes foram sempre maiores para as aves Hy Line. No entanto, tanto as aves Hisex brancas como as marrons apresentaram maiores quantidades de água corporal à maturidade, assim como taxas máximas à maturidade mais tardias. Esse resultado explica a semelhança no ganho de peso entre as linhagens estudadas, visto que, para os demais componentes corporais, as aves Hy Line apresentaram maiores taxas de deposição.

Uma vez determinada a composição do ganho de peso semanal, analisando-se as equações obtidas para PB e gordura, observa-se que a relação proteína bruta/gordura (PB/Gord) diminuiu com o aumento do PV e na chegada da maturidade (Figura 7). No entanto, os processos para atingir a puberdade nos animais são muito complexos, sendo improvável que apenas um fator esteja envolvido neste mecanismo (Foxcroft, 1980).

Em estudos sobre a composição corporal das aves no início da vida produtiva, Kwakkel (1999) fez a seguinte indagação: "qual a composição corporal necessária para engatilhar os sistemas fisiológicos (endócrino) e iniciar o desenvolvimento do trato reprodutivo?" Pelos resultados obtidos neste trabalho, verificam-se mudanças na composição corporal das aves com o avançar da idade, sobretudo 
Tabela 7 - Taxas de deposição de gordura corporal das linhagens semipesadas

Table 7 - Deposition rates of body fat of semi heavy strains

\begin{tabular}{|c|c|c|c|c|c|c|c|}
\hline \multirow[t]{2}{*}{$\begin{array}{l}\text { Idade (dias) } \\
\text { Age (days) }\end{array}$} & \multicolumn{3}{|c|}{$\begin{array}{l}\text { Hy Line Marrom } \\
\text { Hy Line Brown }\end{array}$} & \multicolumn{4}{|c|}{$\begin{array}{l}\text { Hisex Marrom } \\
\text { Hisex Brown }\end{array}$} \\
\hline & $\begin{array}{c}\text { Gordura corporal }(\mathrm{g}) \\
\text { Body fat }(\mathrm{g})\end{array}$ & $\begin{aligned} \text { Taxa } & (\mathrm{g} / \text { dia }) \\
\text { Rate } & (g / \text { day })\end{aligned}$ & $\begin{array}{c}\text { Crescimento relativo }(\%)^{*} \\
\text { Relative growth }(\%)^{*}\end{array}$ & $\begin{array}{r}\text { Gordura corporal } \\
\text { Body fat }(\mathrm{g})\end{array}$ & $\begin{array}{l}\text { (g) Taxa } \\
\text { Rate }\end{array}$ & $\begin{array}{l}(\mathrm{g} / \mathrm{dia}) \\
(\mathrm{g} / \text { day })\end{array}$ & $\begin{array}{c}\text { Crescimento relativo }(\%)^{*} \\
\text { Relative growth (\%)* }\end{array}$ \\
\hline 1 & 2,07 & - & & 5,82 & & - & \\
\hline 7 & 3,47 & 0,20 & & 7,99 & & 0,31 & \\
\hline 14 & 6,00 & 0,36 & 80,71 & 11,31 & & 0,47 & 53,00 \\
\hline 35 & 22,64 & 1,06 & 36,03 & 28,41 & & 1,01 & 26,11 \\
\hline 42 & 32,31 & 1,38 & 30,68 & 37,2 & & 1,26 & 23,80 \\
\hline 49 & 44,45 & 1,73 & 25,54 & 47,92 & & 1,53 & 21,96 \\
\hline 56 & 59,2 & 2,11 & 21,50 & 60,78 & & 1,84 & 19,96 \\
\hline 63 & 76,55 & 2,48 & 17,63 & 75,96 & & 2,17 & 18,04 \\
\hline 70 & 96,43 & 2,84 & 14,58 & 93,63 & & 2,52 & 16,40 \\
\hline 105 & 224,41 & 4,04 & 3,44 & 223,01 & & 4,50 & 9,80 \\
\hline 112 & 253,22 & 4,12 & 1,98 & 257,25 & & 4,89 & 8,73 \\
\hline 119 & 282,21 & 4,14 & 0,62 & 294,15 & & 5,27 & 7,77 \\
\hline 126 & 311,06 & 4,12 & $-0,48$ & 333,57 & & 5,63 & 6,83 \\
\hline
\end{tabular}

* Exemplo: crescimento relativo $(\%)=[($ taxa da semana 56/taxa da semana 49 $) * 100]-100$

* Example: relative growth $(\%)=[($ Weekly rate 56/Weekly rate 49)*100]-100.

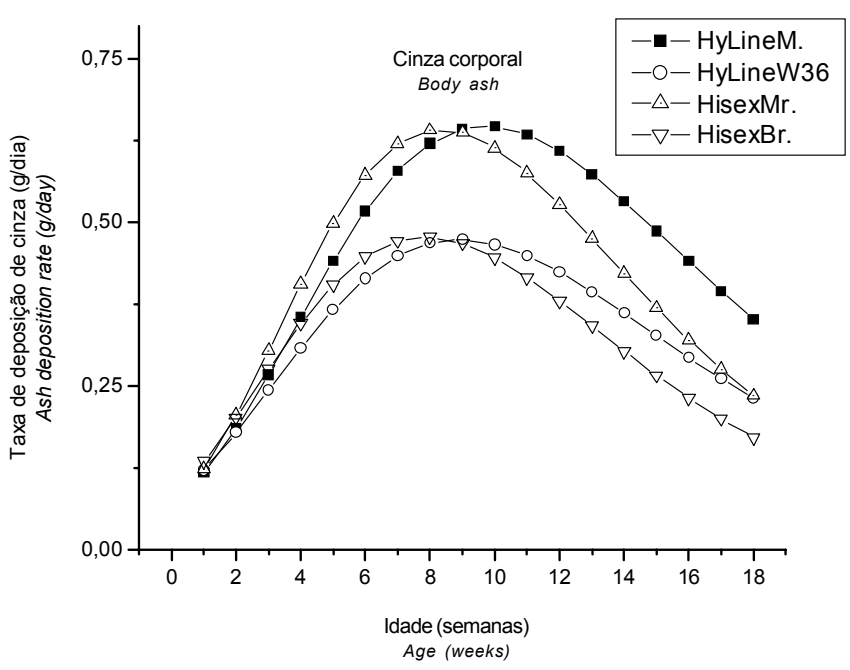

Figura 5 - Efeito da idade e da linhagem sobre a taxa de deposição de cinzas.

Figure 5 - Ash deposition rate according to the age and strain.

no que concerne à relação $\mathrm{PB} / \mathrm{Gord}$. Esta mudança provavelmente está relacionada aos sinais fisiológicos iniciais do desenvolvimento do sistema reprodutivo.

\section{Conclusões}

Apesar dos pesos corporais semelhantes entre as linhagens de mesma categoria, houve variação na composição

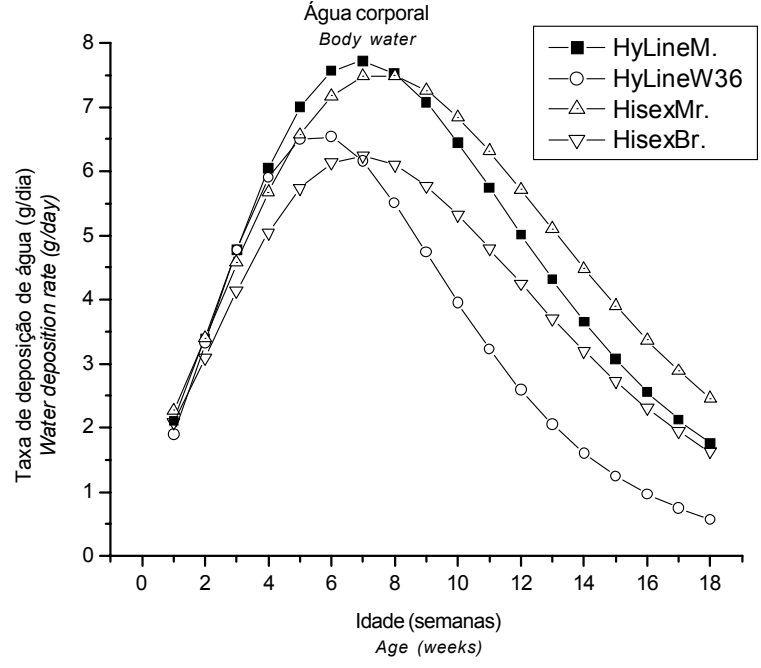

Figura 6 - Efeito da idade e da linhagem sobre a taxa de deposição de água na carcaça.

Figure 6 - Body water rate according to the age and strain.

corporal e nas taxas de crescimento para os diferentes componentes corporais estudados, o que pode influenciar os requerimentos nutricionais das aves. Portanto, o peso corporal, per se, não representa um indicativo seguro da maturidade sexual as aves.

O estudo do potencial de crescimento e da composição corporal é importante para a definição das exigências nutricionais e, principalmente, das deposições de proteína 


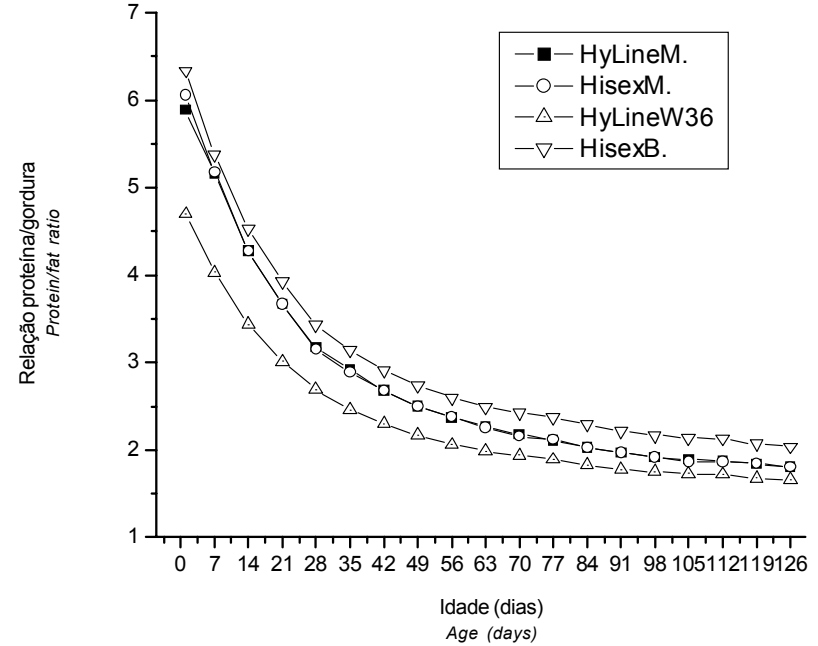

Figura 7 - Efeito da idade e da linhagem sobre a relação proteína bruta/gordura corporal.

Figure 7 - Body crude protein:fat ratio according to the age and strains.

e gordura, pois auxilia na elaboração de programas alimentares adequados para frangas, de forma a promover melhorias no desempenho produtivo da atividade.

\section{Literatura Citada}

BALNAVE, D. Biological factors affecting energy expenditure. In: MORRIS, T.R.; FREMAN, B.M. (Eds.). Energy requirements of poultry. Edinburgh: British Poultry, 1974. p.25-46. (Poultry Science Symposium, 9)

BAKER, E.R. Body weight and the initiation of puberty. Clinical Obstetrics Gynecology, v.28, n.3, p.573-579, 1985.

BOEKHOLT, H.A; van der GRINTEN, P.H.; SCHREUS, V.V.A.M. et al. Effect of dietary energy restriction on retention of protein, fat and energy in broiler chickens. British Poultry Science, v.35, p.603-614, 1994.

BRACCINI NETO, J.; SILVEIRA JR., P.; DIONELLO, N.J.L. Utilização da transformação logarítmica no ajustamento de curvas de crescimento em aves de postura. In: SIMPÓSIO DE ESTATÍSTICA APLICADA À EXPERIMENTAÇÃO AGRONÔMICA, 5., 1993, Porto Alegre. Anais... Porto Alegre: 1993. p.53.

BRODY, T.B.; SIEGEL, P.B.; CHERRY, J.A. Age, body weight and body composition requirements for the onset of sexual maturity of dwarf and normal chickens. British Poultry Science, v.25, p.245-252, 1984.

EMMANS, G.C.; DUN, P. Feather loss in layers. ADAS Ministry of Agriculture, Fisheries and Food, Gleadthorpe Experimental Husbandry Farm, 1980. p.46-53 (Poultry Booklet, 7)

FOXCROFT, G.R. Growth and breeding performance in animals and birds. In: LAWRENCE, T.J.L. (Ed.) Growth in animals. London: Butterworths, 1980. p.229-247.
FUKAYAMA, E.H.; SAKOMURA, N.K.; NEME, R. et al. Efeito da temperatura ambiente e do empenamento sobre o desempenho de frangas leves e semipesadas. Ciência e Agrotecnologia, v. 29, p. $1272-1280,2005$

HUGHES, B.O. Feather damage in hens caged individually. British Poultry Science, v.21, p.149-154, 1980.

KESSLER, A.M.; SNIZEK, P.N. Considerações sobre a quantidade de gordura na carcaça do frango. In: REUNIÃO ANUAL DA SOCIEDADE BRASILEIRA DE ZOOTECNIA, 2001, Piracicaba. Anais... Piracicaba: Sociedade Brasileira de Zootecnia, 2001. p.111-159.

KESSLER, A.M.; SNIZEK, P.N.; BRUGALLI, I. Manipulação da quantidade de gordura na carcaça de frangos. In: CONFERÊNCIA APINCO DE CIÊNCIAS E TECNOLOGIA AVÍCOLA, 2000, Campinas. Anais... Campinas: Fundação APINCO de Ciência e Tecnologia Avícolas, 2000. p.107-133.

KWAKKEL, R.P. Rearing the layer pullet - A multiphasic approach In: Wiseman, J.; GARNSWORThY, P.C. (Eds.) Recent development in poultry nutrition. 2.ed. Nottingam: Nottingam University Press, 1999. p.227-249.

LEESON, S. Nutritional considerations of poultry during heat stress. World's Poultry Science Journal, v.42, p.69-81, 1986.

LONGO, F.A. Estudo do metabolismo energético e do crescimento de frangos de corte. Jaboticabal: Universidade Estadual Paulista, 2000. 76p. Dissertação (Mestrado em Zootecnia) - Universidade Estadual Paulista, 2000.

LOPES, P.S. Curvas de crescimento, análise econômica e estudo de índices de seleção para aves Leghorne. Viçosa, MG: Universidade Federal de Viçosa, 1983. Dissertação (Mestrado em Zootecnia) - Universidade Federal de Viçosa, 1983.

RABELLO, C.B.V. Equações de predição das exigências de energia e proteína para aves reprodutoras pesadas na fase de produção. Jaboticabal: Universidade Estadual Paulista, 2001. 121p. Tese (Doutorado em Zootecnia) - Universidade Estadual Paulista, 2001.

RICKEFS, R.E. Modification of growth and development of muscles in poultry. Poultry Science, v.64, p.1563-1576, 1985.

ROSTAGNO, H.S.; ALBINO, L.F.T.; DONZELE, J.L. et al. Tabelas brasileiras para aves e suínos: composição de alimentos e exigências nutricionais. Viçosa, MG: Universidade Federal de Vçosa, 2000. 141p.

SILVA, D.J.; QUEIROZ, A.C. Análise de alimentos (Métodos químicos e biológicos). 3.ed. Viçosa, MG: Universidade Federal de Viçosa, 2002. 166p.

STATISTICA, 1996. Version Release 5.1. for windows.

STEEL, R.G.D.; TORRIE, J.H. Analysis of covariance, In: Principles and procedures of statistics: a biometrical approach. New York: McGraw-Hill, 1980. p.401-437.

SUMMERS, J.D. Proceedings of the Maryland nutrition conference for feed manufacturers. Belville: 1983. p.12-18.

THONNEY, M.I.; ROSS, D.A. Composition of gain of rats fed low ou high protein diets and grown at controlled rates from 80 to 205 grams. Journal of Nutrition, v.117, p.2135-2141, 1987.
Recebido: $15 / 10 / 04$ Aprovado:23/01/06 